\title{
REFLEXÕES SOBRE A DISCIPLINA DE TECNOLOGIAS DA INFORMAÇÃO E DA COMUNICAÇÃO EM UMA INSTITUIÇÃO DE ENSINO SUPERIOR NO MUNICÍPIO DE FLORIÁNO - PIAUÍ
}

Simone Fernanda Silva Magalhães - IFPI - Campus Floriano/PI - sfernandasm@ gmail.com Marlise Geller - PPGECIM - ULBRA - marlise.geller@gmail.com

Resumo: Este artigo apresenta algumas considerações obtidas em uma pesquisa cujo objetivo principal é investigar as reflexões sobre a disciplina de Tecnologias da Informação e da Comunicação (TIC) junto a alunos e professores dos cursos de licenciatura em Biologia e Matemática em uma instituição de ensino superior no município de Floriano - Piauí. É uma pesquisa qualitativa, do tipo estudo de caso, que apontou indícios de que tanto alunos quanto professores da referida disciplina necessitam vincular-se a práticas pedagógicas mais condizentes com os objetivos, habilidades e competências propostas a essa unidade curricular.

Palavras-chave: Tecnologias da Informação e Comunicação; Ferramentas Virtuais de Comunicação; Ambiente Virtual de Aprendizagem.

Abstract: This article presents some considerations obtained from a research whose main objective is investigate the reflections on the matter of Information and Communication Technology (ICT) with students and teachers of graduate courses in Biology and Mathematics at an institution of higher education the city of Floriano Piauí. This case study is a qualitative research showing some evidence that students and teachers of this matter need to be bound by teaching practices more consistent with the objectives and competencies that the proposed course.

Keywords: Information and Communication Technology; Virtual Tools of Communication; Virtual Learning Environment.

\section{Introdução}

No limiar do final da primeira década do século XXI, frente a tantos desafios que a Educação brasileira enfrenta, a familiarização com as Tecnologias da Informação e da Comunicação (TIC), como recurso pedagógico favorável ao processo de ensinoaprendizagem, ainda é vista por muitos professores como tendência, pelos mais otimistas, ou como modismo, pelos mais céticos (BONASSINA, 2008; GADOTTI, 2000; MACHADO, 2007; MENEGOTTO, 2006; MORAN, 1997, 2004, 2007, 2008; MOREIRA, 2009, OLIVEIRA, 2006; PALLOFF e PRATT, 2004; PRIMO, 2000).

Essas reflexões são comuns tanto aos docentes que já estão em pleno exercício de sua formação, em programas de capacitação ou de educação continuada, tanto por aqueles que ainda estão em formação. É preciso prepará-los para aprender, entender e aplicar didaticamente as TIC sem que se preocupem com o valor instrumental delas.

Sendo essa premissa uma das mais importantes para delinear e definir o nosso objeto de estudo, arrolamos as reflexões de alunos e professores dos cursos de licenciatura em Biologia e Matemática de uma instituição de ensino superior (IES), localizada no município de Floriano - Piauí, quanto à formação recebida em TIC, já que 
o currículo desses cursos estabelece que os licenciandos devem iniciar sua familiarização com tais recursos logo no primeiro semestre.

Há tempos, as TIC como os computadores e seus periféricos e a Internet não são particularidades dos cursos da área de computação ou informática. Elas são necessárias para a formação de qualquer profissional disposto a lidar com as diferentes situações e problemas advindos das transformações sociais provocados por avanços tecnológicos.

\section{Tecnologias da Informação e da Comunicação na Educação}

Se as TIC estão no cenário atual como fatores de mudança social, elas também favoreceram mudanças de paradigmas atingindo rápida e mundialmente todos os setores como o comércio, a indústria, a economia e, como não poderia deixar de ser, ainda que de forma mais lenta, a educação.

O sistema educacional brasileiro tem se voltado para a capacitação dos seus gestores, professores e alunos, e entre os projetos que a maioria das instituições vem oferecendo surgem, aqui ou ali, os de qualificação em alguma das tecnologias da modernidade como computador, internet, celular, câmera digital, calculadoras eletrônicas, lousa interativa, entre outros.

Compreender que as TIC não são simplesmente novas ferramentas ou novos recursos instrumentais, mas sim recursos aliados a novas oportunidades de ensino que afloram possibilidades para desenvolvimento da criatividade, da aprendizagem e da reconstrução dos conhecimentos, requer o rompimento de muitas barreiras. Barreiras tais, como as crenças quanto ao seu papel profissional, quanto ao perfil dos seus alunos que já utilizam as ferramentas de forma familiar, quanto à natureza do ofício de lecionar, que cada vez mais exige a troca de experiências e informações entre seus pares e desses para com os educandos, e quanto à eficácia das atividades promovidas com a integração da tecnologia em si. Essa resistência às mudanças nas crenças dos professores só se rompe na medida em que começam a enxergar os benefícios para si mesmos e quando dominam "o porquê" e "para que" utilizar as TIC. (OLIVEIRA, 2006)

É importante não dispensar os avanços científicos e tecnológicos ocorridos no mundo como o da evolução das TIC, que podem e devem ser usadas na educação, seja na modalidade presencial ou a distância, ou em ambas.

Para tanto, é necessário promover a "alfabetização tecnológica do professor" (SAMPAIO E LEITE, 2003), não tratando apenas de aprender a utilizar os recursos tecnológicos, mas de compreender o domínio crítico que a linguagem tecnológica endossa.

\section{Ferramentas Virtuais de Comunicação}

Indubitavelmente, a Internet é um dos maiores veículos de promoção das ações mais importantes dos tempos atuais como a localização de informações e a comunicação. Essas ações são realizadas através de serviços, dispositivos, recursos ou ferramentas virtuais de comunicação, tais como ferramentas de busca, correio eletrônico, comunicadores instantâneos, salas de bate-papo, blogs, telefonia virtual, fóruns de discussão, entre outros.

A mediação pedagógica, a interação, a colaboração e a cooperação entre professores/alunos, alunos/alunos, professores/professores frente às TIC podem ser mais estimulantes com a utilização das ferramentas virtuais de comunicação, sobretudo 
quando disponibilizadas em conjunto nos denominados Ambientes Virtuais de Aprendizagem (AVA).

\subsection{Ambientes Virtuais de Aprendizagem}

Os ambientes virtuais de aprendizagem (AVA) são espaços na Internet que enriquecem o processo de ensino e aprendizagem através das possibilidades de desenvolvimento de atividades como debates em fóruns, discussão de solução de problemas por meio dos chats e troca de idéias por meio de textos, materiais de apoio, aplicativos e e-mails entre os seus participantes, que podem estar em posições geográficas iguais ou diferentes, bem como conectados ou não simultaneamente.

Porém cabe lembrar que os AVA não são garantias em si mesmos de que os projetos e experiências desenvolvidos neles sejam sempre de sucesso, uma vez que "nesses ambientes, a tecnologia é apenas um meio, pois a ênfase deve estar na proposta, no conteúdo pedagógico e no desenvolvimento do processo educativo" (PEREIRA, 2007, p. 2).

Abreu (2007) também aduz que o uso das ferramentas virtuais de informação e comunicação presentes nos AVA deve promover a interação e estas devem ser aplicadas em articulação com propostas pedagógicas que visem potencializar o conhecimento através da realização de atividades, projetos ou ações educativas.

Para Ribeiro, Mendonça e Mendonça (2007, p.5), os AVA "permitem desenvolver as atividades no tempo, espaço e ritmo de cada participante", por conta da possibilidade dos encontros presenciais, semipresenciais ou totalmente a distância. Aumentam-se, assim, as chances de comunicação, de troca de informações e até de experiências entre os participantes que podem estabelecer parcerias para colaborarem e cooperarem, tendo em vista a interação promovida por tais ambientes.

\section{A disciplina de TIC nos cursos de Biologia e Matemática}

Os cursos de Licenciatura em Biologia e em Matemática da instituição investigada têm duração de quatro anos organizados em oito módulos.

Ambos os currículos estão estruturados em cinco núcleos de formação: Núcleo de Formação dos Professores de Biologia/Matemática; Núcleo de Formação dos Professores da Educação Básica; Núcleo de Formação dos Professores Especialistas; Núcleo de Formação em Campos Específicos de Atuação com opção em Educação de Jovens e Adultos e em Educação Especial.

Nesses cursos ainda consta um Núcleo Articulador da Prática Profissional de 800 horas, discriminadas no estágio curricular supervisionado (400 horas) e na prática como componente curricular (CC, 400 horas). Dessas, 320 horas estão distribuídas nos temas e as 80 horas restantes em seminários de contextualização realizados ao final de cada módulo. Na carga-horária total desses cursos ainda estão incluídas elaboração do Trabalho de Conclusão de Curso (TCC, 75 horas), disciplinas optativas (120 horas) e atividades acadêmico-científico-culturais (200 horas).

A disciplina de Tecnologia da Informação e da Comunicação está inserida no grupo do núcleo de formação dos professores da educação básica. A carga-horária para este componente curricular é de 45 horas e sua ementa consta dos seguintes conteúdos: Introdução à informática; Sistema operacional; Internet como recurso educativo; Informática educativa; Softwares aplicativos.

De acordo com a definição da instituição são propostas as seguintes competências 
e habilidades para este ementário:

- Compreender a importância da informática educativa para o processo de ensino e aprendizagem;

- Utilizar as novas teorias de informação e comunicação, analisando as diversas modalidades de uso do computador no processo pedagógico;

- Desenvolver atividade de softwares aplicativos com fins educativos;

- Pesquisar, avaliar e testar softwares educativos;

- Acessar a Internet como uma estratégia de aprofundamento do conhecimento.

Na IES investigada, os coordenadores dos cursos organizam o horário das turmas para que as disciplinas de 45 horas, como é o caso da disciplina em questão, sejam ministradas em três aulas consecutivas em um único dia da semana.

Os cursos de licenciatura nessa instituição são ofertados apenas no turno noturno, cujas aulas têm a duração de 50 minutos. Sendo assim, para que os professores cumpram a carga-horária indicada para a disciplina são necessárias 54 aulas.

Assim, a descrição e aplicação da referida unidade curricular tem seus objetivos e ementas muito peculiares para cada instituição. Mas também podemos identificar algumas convergências ao trabalhar as TIC, como por exemplo, treinamento básico em ferramentas e ambientes informatizados e até quanto ao necessário aprimoramento de recursos em ambientes virtuais de aprendizagem.

\section{Procedimentos Metodológicos}

O estudo teve a duração de um semestre letivo, iniciado no mês de fevereiro e encerrado no mês de junho de 2009. Os sujeitos da investigação foram os licenciandos do Módulo I dos cursos de Biologia (42 alunos) e de Matemática (44 alunos) em uma instituição de ensino superior no município de Floriano - Piauí, matriculados na disciplina de TIC e os professores que a ministravam.

A pergunta norteadora de nossa pesquisa é Como os alunos e professores de licenciatura em Biologia e Matemática de uma instituição de ensino superior no município de Floriano - Piauí refletem sobre a formação recebida na disciplina de Tecnologias da Informação e da Comunicação (TIC)?

Por isso, utilizamos os pressupostos de uma pesquisa qualitativa do tipo estudo de caso, pois segundo Fiorentini e Lorenzato (2006) o estudo de caso é recomendável:

[...] quando se quer estudar algo singular, que tenha um valor em si mesmo. [...] Pode ser qualquer "sistema delimitado" que apresenta algumas características singulares e que fazem por merecer um investimento investigativo especial por parte do pesquisador. [...] Por isso, o estudo de caso tende a seguir uma abordagem qualitativa (p. 110).

Sendo assim, com o intuito de efetivar tal investigação, inicialmente, procedemos com a revisão bibliográfica permeando os temas referentes às discussões mais pertinentes à pesquisa: aplicação e utilização de TIC, ferramentas virtuais de comunicação e AVA. Essa fase ladeou-se desde a delineação e definição de nosso objeto de estudo até a fase das considerações finais e conclusões.

A fase seguinte consistiu no planejamento dos modos e técnicas que validassem o estudo de caso em questão. Dentre os instrumentos de coleta de informações, optamos pela aplicação de questionários e pela prática social da pesquisa em campo através do acompanhamento das aulas normais da disciplina de TIC, observando em classe como os professores a ministravam.

Procedemos, então, com a aplicação de questionários para os referidos alunos: um no início e outro ao final do semestre letivo. 
Visando enriquecer as análises desse estudo, paralelamente ao acompanhamento em classe das aulas de TIC, no início do período letivo (mês de março), procedemos com a abertura de uma turma em ambiente virtual do programa Escola Técnica Aberta do Brasil (ETEC Brasil ${ }^{1}$ ).

Essa turma constitui-se de um ambiente virtual de aprendizagem, cujo propósito principal foi conduzir os professores e os alunos da disciplina de TIC a experimentarem os recursos dispostos no ambiente e instigá-los a utilizarem um fórum de discussão, inserindo tópicos que registrassem suas opiniões quanto às vantagens e desvantagens das ferramentas virtuais de comunicação mais simples como correio eletrônico, sala de bate-papo e o próprio fórum.

Ao final do semestre letivo, após analisarmos os dois questionários dos referidos alunos e de identificarmos as opiniões dos sujeitos cadastrados no AVA quanto ao uso das ferramentas virtuais de comunicação, resolvemos aplicar um questionário com os professores de TIC.

Optamos por preservar o anonimato dos sujeitos da investigação identificando os alunos como Aluno Bio 1, Aluno Bio 2,..., até Aluno Bio 42 e Aluno Mat 1, Aluno Mat $2, \ldots$, até Aluno Mat 44; e os professores de TIC como Professor Bio e Professor Mat.

\section{Resultados e Discussão dos Dados}

Iniciamos nossa discussão com a análise das respostas do primeiro questionário cujo principal intuito foi averiguar quais alunos tinham acesso a computador com Internet, bem como conhecer as suas expectativas em relação à disciplina de TIC.

A turma de Biologia era predominantemente feminina (67\% da turma), cuja média de idade é de 21 anos. Já a turma de Matemática era predominantemente masculina (64\% da turma), cuja média de idade é de 23 anos.

Para nossa pesquisa interessava saber se os sujeitos investigados estariam preparados para participar de uma experiência com TIC, utilizando ferramentas virtuais de comunicação dispostas em um AVA. Para tanto, era necessário questionar se tinham acesso a computador com Internet, bem como se já dispunham de alguma experiência com recursos e/ou serviços disponibilizados na Internet.

De acordo com as informações obtidas, dos 42 alunos de Biologia, apenas 1 não possui acesso a computador com Internet e dos 44 de Matemática, 4 não possuem. Assim, concluímos que apenas aproximadamente $6 \%$ dos licenciandos investigados não estariam preparados a participar da experiência em um AVA que fora preparado para dar suporte extraclasse à disciplina de TIC.

Constatamos que apenas cerca de $20 \%$ de todos os alunos dispõem de acesso em casa. A maioria dos entrevistados (aproximadamente 63\%) acessa a Internet por meio de casas especializadas nesse tipo de serviço, denominadas de Lan House. Nenhum dos alunos tem acesso a computador com Internet na instituição investigada. Isto se dá porque, desde o início do período letivo do corrente ano, houve a suspensão do link de acesso à Internet aos laboratórios de Informática, de onde os alunos de qualquer curso poderiam fazer uso.

Quando inquiridos a respeito de possuírem ou não e-mail, localizamos que 35

\footnotetext{
${ }^{1}$ É um programa de formação profissional técnica a distância, que se constitui em uma das ações do Plano de Desenvolvimento da Educação, cujo objetivo principal é a democratização do acesso ao ensino técnico público, através da modalidade de educação a distância, levando cursos técnicos aos municípios mais distantes das instituições de ensino técnico, incentivando os jovens a concluírem o ensino médio.
} V. 7 No 3, dezembro, 2009 
alunos da turma de Biologia possuem e apenas 7 não utilizam ainda esse tipo de serviço. Na turma de Matemática 36 possuem e apenas 8 desses alunos não possuem.

Essas situações comprometem a competência/habilidade: acessar a Internet como uma estratégia de aprofundamento do conhecimento, que o plano da disciplina TIC propõe a ser atingida, já que 78 dos alunos investigados utilizam a rede mundial de computadores mais para a pesquisa de informações e para se comunicar com os amigos e parentes por meio de e-mail (58 alunos) e comunidades virtuais como Orkut (59 alunos).

Um fator que contribui para a pouca utilização das TIC, mesmo aquelas relacionadas à Internet, pode ser a falta de apresentação e discussão da importância das mesmas, como propõe outra das competências/habilidades indicadas no plano da disciplina: utilizar as novas teorias de informação e comunicação, analisando as diversas modalidades de uso do computador no processo pedagógico.

No segundo questionário os alunos assinalaram que a disciplina de TIC é importante para sua formação no curso e para sua (futura) prática pedagógica, mas nenhum deles pontuou como ÓTIMO a resposta para a seguinte questão: Na sua avaliação que conceito você daria a disciplina de TIC quanto à formação que recebeu nesse período?

As reflexões apresentadas pelos alunos nas demais questões dos instrumentos de pesquisa demonstram o anseio deles por uma maior familiarização com as ferramentas e serviços da Internet. Mas a falta de estruturação institucional e educacional dificulta esse processo. Embora sem tanta facilidade de acesso e mesmo não tendo condições de participar do AVA da experiência, os alunos reconhecem a importância das ferramentas virtuais de comunicação.

Percebemos que a principal dificuldade quanto à utilização das ferramentas não está no recurso em si, mas sim relacionada à falta de acesso a computadores com Internet.

Também analisamos as reflexões sobre a disciplina de TIC junto aos professores que a ministraram no período da investigação. O Professor Bio tem habilitação em Tecnologia em Processamento de Dados com especialização em Análise de Sistemas. O Professor Mat tem sua formação em Bacharelado em Ciência da Computação e especialização em Desenvolvimento para Web.

Observamos que as visões desses professores sobre a disciplina de TIC podem estar diretamente relacionadas com a própria formação que tiveram, pois os cursos de Tecnologia e Bacharelado de Computação/Informática promovem a utilização da Informática como fim, não como meio.

Para a questão: Se você fosse designado para elaborar um novo Plano de Disciplina para unidade curricular TIC como constituiria a sua ementa, a cargahorária e quais ferramentas/softwares de apoio escolheria? os professores apontam que:

O plano de disciplina que me foi apresentado está ótimo. Apenas é preciso que se ofereçam condições para aplicabilidade, alcançando assim os objetivos propostos. (Professor Bio).

Carga-horária de 90; Ferramentas: Office, Nero, Acrobat, Winrar; Ementa: Operações básicas do Windows; Instalação de SO (teoria e prática); Trabalhando com Access. (Professor Mat).

Percebemos algumas fragilidades para que a unidade curricular TIC pudesse ser desenvolvida a contento para o desenvolvimento das competências e habilidades propostas nos projetos de ambos os cursos como, por exemplo, o fato de não terem sido 
aplicados conteúdos ou atividades relacionadas a softwares educativos, nem a análise de diversas modalidades de uso do computador no processo pedagógico. Os conteúdos Internet como recurso educativo e Informática educativa também não foram desenvolvidos pelos professores de TIC nesse período da investigação.

A experiência no AVA foi proposta mesmo consciente da falta de acesso à Internet na instituição. Isso porque concordamos com Pereira (2007) ao afirmar que o processo de ensino e aprendizagem pode ser potencializado pelos ambientes virtuais de aprendizagem.

Levando em consideração o fato de que a maioria dos alunos teria que pagar o seu acesso em alguma Lan House, tivemos que optar pela participação voluntária de todos os que foram cadastrados. Ainda assim, obtivemos uma expressiva participação, se levarmos em consideração o número de interações ocorridas no ambiente.

Foram registrados 33 tópicos de discussão no fórum do AVA que fora aberto para que os participantes pudessem manifestar sua opinião quanto às vantagens e desvantagens das ferramentas virtuais de comunicação como o correio eletrônico, o próprio espaço de fórum e da sala de bate-papo. A seguir resgatamos o depoimento do aluno Mat 19 e Bio 17:

As vantagens do Fórum são: a possibilidade de resolução de um dado problema, compartilhado entre uma comunidade e o aprendizado de acordo com a área do fórum, visto que várias pessoas compartilhar inúmeros problemas diferentes, e consequentemente várias soluções para os mesmos.

Ao meu ver a única desvantagem seria não existir no fórum pessoas qualificadas para responder as dúvidas de seus membros (e isso é bem difícil hoje em dia).

Em relação ao bate-papo as vantagens são: interação em tempo real e possível resolução de uma dúvida em curtíssimo espaço de tempo. Como desvantagem, ser utilizado de maneira incorreta e para fins que não os de resolução e/ou aprendizado de algo, como por exemplo ao invés de utilizar um chat técnico para resolução de problemas algumas pessoas utilizam-no para conversar pessoais e sem nenhum valor técnico. Sobre o correio, cito como vantagens a comunicação, rápida e segura por um preço relativamente baixo e o envio de respostas em tempo real. Não vejo desvantagens na utilização dos correios eletrônicos. (Aluno Mat 19).

Como vantagens do fórum, considero a interação entre os alunos um podendo ajudar o outro e as diversidades de respostas. Já como desvantagem a dificuldade de acesso, provocada pela falta de internet na instituição e a qualidade de algumas respostas nem sempre serão satisfatórias.

Em relação ao correio eletrônico, as vantagens são receber mensagens quando estivermos ausente e enviar mensagens a todos os usuários ao mesmo tempo. As desvantagens são referentes ao limite de arquivos e a invasão de privacidade. As vantagens da sala de bate-papo: facilita o contato pessoal e a conversa pode ser feita a distancia em tempo real. Como desvantagens, verifico a dificuldade de acesso pra quem não é capacitado virtualmente e o espaço de tempo curto para as resposta. (Aluno Bio 17).

As respostas apontadas confirmam as reflexões de Machado (2007), que analisou o fórum de discussão como mais uma ferramenta virtual de comunicação que pode servir de apoio ou "auxílio à resolução de problemas".

Depoimentos de alunos atestam que a ferramenta fórum é mesmo um importante aliado quando grupos de pessoas se disponibilizam a discutir e/ou analisar coletivamente determinados assuntos.

\section{Conclusões}

V. $7 \mathrm{~N}^{\mathrm{o}}$ 3, dezembro, 2009 
Promover a familiarização de alunos e professores dos cursos de licenciatura da IES investigada com as tecnologias principalmente oriundas dos avanços da Informática tais como computador e Internet, para garantia das habilidades e competências indicadas para a unidade curricular de TIC, motivou e justificou nosso interesse por essa investigação.

Dentre as várias possibilidades de alcançar os objetivos propostos, optamos por instigar todos os sujeitos envolvidos a experimentar a aplicabilidade de algumas das TIC advindas da Internet, por meio de um ambiente virtual de aprendizagem, no processo de apoio extraclasse, com as ferramentas virtuais de comunicação mais simples e usuais como correio eletrônico, fórum de discussão e sessões de bate-papo.

Infelizmente, ao iniciarmos nossa investigação não contávamos com a falta de disponibilidade de acesso à Internet na IES da pesquisa, pois até o mês de janeiro do corrente ano, quando sondamos as viabilidades de propostas para estudos, havia um link de $128 \mathrm{Kbps}$ disponibilizado pela única empresa provedora de Internet na cidade de Floriano, cujo contrato foi suspenso.

O fato é que, sem acesso à Internet, a IES investigada fica incapacitada de desenvolver atividades que permitam uma maior interatividade entre professores e alunos através da Internet, como as plataformas virtuais de aprendizagem.

A acessibilidade virtual é praticamente um pré-requisito sustentado pelas políticas públicas de Informática Educativa do Governo quando, por exemplo, exige-se que as inscrições de exames para determinados alunos e cursos de capacitação de professores só possam ser feitos pelos portais de Internet.

Nossa pesquisa apontou alguns indícios de que os alunos e professores da disciplina de TIC que a IES investigada oferta nos cursos de Licenciatura de Biologia e Matemática precisam vincular-se a práticas pedagógicas mais condizentes com os objetivos, habilidades e competências propostas a essa unidade curricular.

Para tanto, é necessário recompor a distribuição do conteúdo programático da disciplina de TIC para que docentes e discentes mergulhem mais profundamente nas questões que tratam das tecnologias educacionais, tendo em vista compreender, assimilar e promover a discussão das ações e políticas enlaçadas no tocante à Informática na Educação para favorecer o processo ensino-aprendizagem e não restringi-la ao aprendizado das unidades que compõem o computador e utilização de certos aplicativos.

Propomos, assim, uma divisão da unidade curricular TIC da instituição em pelo menos dois módulos de 45 horas cada, sendo que o primeiro preocupe-se em trabalhar as noções básicas de informática como uma espécie de nivelamento dos alunos que ainda não possuem ou tenham pouco contato com computador; e o segundo módulo enfoque a utilização das TIC como recurso tecnológico no processo de ensinoaprendizagem, construindo uma visão crítica, teórica e prática sobre isso, como sugere a proposta da Universidade Federal de Santa Maria no curso de Licenciatura em Matemática; estimulando os discentes na produção de materiais instrucionais, como sugere a proposta da Universidade Federal de Uberlândia no curso de Licenciatura em Física; discutindo os aspectos psicopedagógicos envolvidos no seu manuseio das TIC e de sua articulação com os conteúdos curriculares específicos, como propõe a Universidade Federal do Espírito Santo nos cursos de Licenciatura em Biologia, Física e Química; capacitando os discentes e docentes a utilizar as TIC através da criação, modelagem, administração e avaliação de AVA, como focaliza a Universidade Presbiteriana Mackenzie nos cursos de Licenciatura em Física e em Matemática. 
Apontamos como aspecto positivo a motivação por parte dos alunos de TIC em utilizar um ambiente virtual de aprendizagem pela primeira vez, mesmo tendo que arcar com uma despesa para acesso à Internet, pois as sessões de bate-papo agendadas no ambiente foram realizadas quase que em sua totalidade aos sábados.

Os resultados dessa pesquisa sugerem que a IES precisa:

- Acompanhar as práticas pedagógicas realizadas no ambiente acadêmico de maneira mais próxima, estimulando a troca de experiências didáticas entre os professores dos cursos, independente da formação ou área de atuação, através de momentos sistematizados de planejamento entre os professores de cada semestre, interrelacionando as unidades curriculares de fundamentação com as unidades curriculares de aplicação.

- Capacitar os docentes em cursos cuja ênfase esteja nas novas metodologias de ensino, inclusive nas novas metodologias educacionais, a partir das TIC, garantindo que ocorra de forma continuada e permitindo assim a constante atualização.

- Restabelecer o mais rápido possível o link de acesso à Internet para permitir a troca de informação, a execução de atividades, trabalhos e projetos via web dos discentes e docentes, bem como viabilizar a implantação de plataformas virtuais de aprendizagem para o desenvolvimento de EAD entre gestores, professores, alunos, monitores, estagiários e comunidade escolar.

\section{Referências}

ABREU, Diana dos Santos. $O$ uso das ferramentas de interação em ambientes virtuais de aprendizagem: um estudo comparativo. Rio de Janeiro, UERJ: 2007. Dissertação de Mestrado. Programa de Pós- Graduação em Políticas Públicas e Formação Humana da Faculdade de Educação da Universidade do Estado do Rio de Janeiro: 2007.

BONASSINA, Ana Lúcia Berno. Ambientes Virtuais de Aprendizagem - uma proposta para inclusão de escolares hospitalizados. Curitiba, PUC-PR, 2008. Dissertação de Mestrado (Mestrado em Educação), Programa de Pós-Graduação em Educação da Pontifícia Universidade Católica do Paraná: 2008.

FIORENTINI, Dario; LORENZATO, Sergio. Investigação em Educação Matemática: percursos teóricos e metodológicos. Campinas, SP: Autores associados, 2006.

GADOTTI, Moacir. Perspectivas Atuais da Educação. Revista São Paulo em Perspectiva. São Paulo, 2000.

MACHADO, Lisandro B. Fórum de discussão como ferramenta de auxílio à resolução de problemas. Dissertação de Mestrado (Mestrado em Ensino de Ciências e Matemática), Programa de Pós-Graduação em Ensino de Ciências e Matemática da Universidade Luterana do Brasil - ULBRA. Canoas: 2007.

MENEGOTTO, Daniela Brun. Práticas pedagógicas on line: os processos de ensinar e de aprender utilizando o AVA-UNISINOS. UNISINOS. São Leopoldo: 2006.

MORAN, José Manuel. Os novos espaços de atuação do professor com as tecnologias. In: CLEBESCH, Júlio. (Org.). Educação 2008 - As mais importantes tendências na visão dos mais importantes educadores. $1^{\text {a }}$ ed. Curitiba: Multiverso, 2008, p. 196-199.

MASETTO, M. T.; BEHRENS, M. (orgs.) Novas tecnologias e mediação pedagógica. 13 $3^{\mathrm{a}}$. ed. Campinas, SP: Papirus, 2007. 173 p. . Integração das tecnologias na educação. $1^{\mathrm{a}}$. ed. Brasília: MEC-SEED, 2005. v. 1.

Tendências da educação pela Internet no Brasil. Educação (UFAL), Maceió, Alagoas, v. 12, n. 20, p. 53-76, 2004.

V. $7 \mathrm{~N}^{\mathrm{o}}$ 3, dezembro, 2009 
Os novos espaços de atuação do professor com as tecnologias. Revista Diálogo Educacional (PUCPR), Curitiba, PR, v. 4, n. 12, p. 13-21, 2004.

. A organização de ambientes presenciais e virtuais de aprendizagem. Cadernos Pedagógicos. São Paulo - SP, v. 1, n. 6, p. 39-43, 2004.

. Educação e Tecnologias: Mudar para valer! (s.d.). Disponível em: < http://www.eca.usp.br/prof/moran/educatec.htm >. Acesso em 11 abr. 2009.

. Como utilizar a Internet na Educação. Revista Ciência da Informação. vol 26, n.2, maio-agosto 1997, pág. 146-153. Disponível em < http://www.eca.usp.br/prof/moran/internet.htm >. Acesso em 12 jul. 2008.

MOREIRA, Manuel Area. Introducción a La Tecnología Educativa. Universidade de La Laguna. España, 2009.

OLIVEIRA, Ramon de. Informática Educativa: Dos planos e discursos à sala de aula. Campinas, SP: Papirus. $11^{\mathrm{a}}$ ed. 2006.

PALLOFF, Rena M.; PRATT, Keith. O aluno virtual: um guia para trabalhar com estudantes on-line. Porto Alegre: Artmed, 2004.

PEREIRA, Alice T. C. Ambientes virtuais de aprendizagem - em diferentes contextos. Rio de Janeiro: Ciência Moderna: 2007.

PRIMO, Alex. Ferramentas de interação na web: travestindo o ensino tradicional ou potencializando a educação através da cooperação? RIBIE 2000, Viña del Mar - Chile. Disponível em: < http://www.c5.cl/ieinvestiga/actas/ribie2000/papers/210/index.htm > Acesso em 08 ago. 2008.

RIBEIRO, Elvia Nunes; MENDONÇA, Gilda Aquino de Araújo e MENDONÇA, Alzino Furtado de. A importância dos ambientes virtuais de aprendizagem na busca de novos domínios da EAD. Anais do $13^{\circ}$ Congresso Internacional de Educação a Distância. Curitiba: 2007.

SAMPAIO, Marisa N.; LEITE, Lígia S. Alfabetização tecnológica do professor. $5^{\mathrm{a}}$ ed. Petrópolis, RJ: Vozes, 2003. 